\title{
Short Latency Somatosensory Evoked Potentials in a Patient with a Cervical Neurinoma
}

\author{
-Case Report-
}

\author{
Tetsuo YokoYama, Hiroshi RYU, Kenichi Uemura, \\ Tsunehiko MIYAMOTO, Toshiaki YAMAMOTO, Yasushi SUGIURA, \\ Toshiaki NINCHOJI, Shoji NAKAJIMA and Tsuneo SAKAI*
}

\author{
Department of Neurosurgery, Hamamatsu University \\ School of Medicine, Hamamatsu, Shizuoka; \\ *Department of Neurosurgery, Mikatagahara General Hospital, \\ Hamamatsu, Shizuoka
}

\begin{abstract}
A 34-year-old male with a right $\mathrm{C} 4$ root neurinoma was operated on and the tumor was totally removed. Short latency somatosensory evoked potentials (SL-SEPs) recorded before operation revealed only $P_{1}\left(P_{9}\right)$ and $N_{1}$ potentials. SL-SEPs were sequentially recorded and compared with changing symptoms and signs in an attempt to identify the primary generator of $\mathrm{P}_{2}\left(\mathrm{P}_{11}\right)$ potential. The recovery of SLSEPs largely corresponded to recovery of vibration and position sensations; $P_{2}$ and following potentials appeared with improvement of these deep sensations. These findings suggest that $P_{2}$ potential may originate in the dorsal column or in a site rostral to the tumor.
\end{abstract}

Key words: spinal root neurinoma, evoked potentials, sensory disturbance, SL-SEPs

\section{Introduction}

Goff $e t$ al. ${ }^{9)}$ first recorded a positive potential with a peak latency of 13 to $17 \mathrm{msec}$ following stimulation of the median nerve with a cephalic reference. Two additional positive potentials preceding this potential were first recorded by $\mathrm{Cracco}^{5,6)}$ with a noncephalic reference.

After Cracco reported his finding of short latency somatosensory evoked potentials (SL-SEPs) in response to median nerve stimulation in man, many investigators ${ }^{1,8,12-16,19)}$ attempted to locate the primary generators of these potentials. Most of these studies employed normal subjects, and the origins of these potentials are still a matter of controversy. Only a few investigators ${ }^{2,4,17)}$ have recorded SL-SEPs in patients with well localized lesions, and their reports are brief. Study of the recovery of SL-SEPs in the context of clinical signs in patients with well localized lesions is necessary, not only to identify the primary generators but also to determine the usefulness of SL-SEPs in clinical practice.

For this purpose we sequentially recorded SLSEPs in a patient with a neurinoma of the right $\mathrm{C} 4$ dorsal root and studied the relationship between SLSEPs and the clinical findings.

\section{Case Report}

A 34-year-old male noticed sensory and motor disturbances of the right upper extremity in February, 1982. The disturbances had extended to his right lower extremity by September of that year. By March of 1983, his left upper and lower extremities were also involved.

On admission to our hospital on April 14, 1983, he

Received January 14, 1985; Accepted August 19, 1985

Authors' present addresses: T. Yamamoto, M.D., and S. Nakajima, M.D., Department of Neurosurgery, Fujinomiya General Hospital, Fujinomiya, Shizuoka, Japan; Y. Sugiura, M.D., Department of Neurosurgery, Yaizu General Hospital, Yaizu, Shizuoka, Japan. 


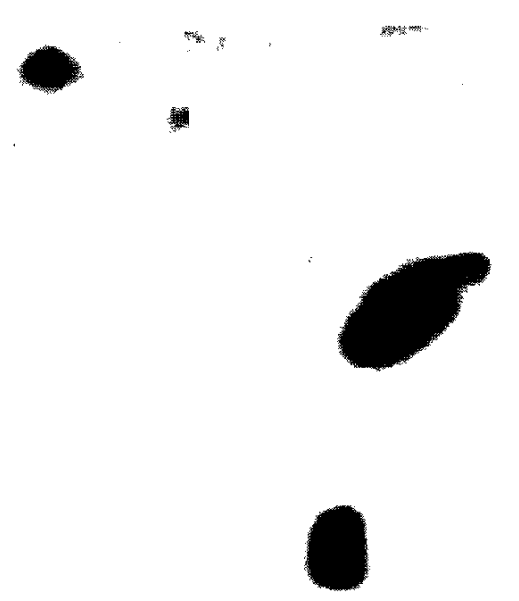

Fig. 1 Metrizamide CT myelography at the C4 level. Note the dumbbell-shaped mass enlarging the right intervertebral foramen and compressing the spinal cord.

had sensory disturbances below the $\mathrm{C} 4$ level; deep sensations (position and vibration) were markedly disturbed compared to superficial sensations. Sensation in the sacral region was spared. Mild motor weakness in the right upper and lower extremities were observed. Bilateral patellar tendon reflexes were increased and clonus was elicited in both ankles.

Computerized tomographic myelography revealed a dumbbell-shaped mass lesion at the $\mathrm{C} 3-\mathrm{C} 4$ level (Fig. 1). On May 25, 1983, a neurinoma arising from

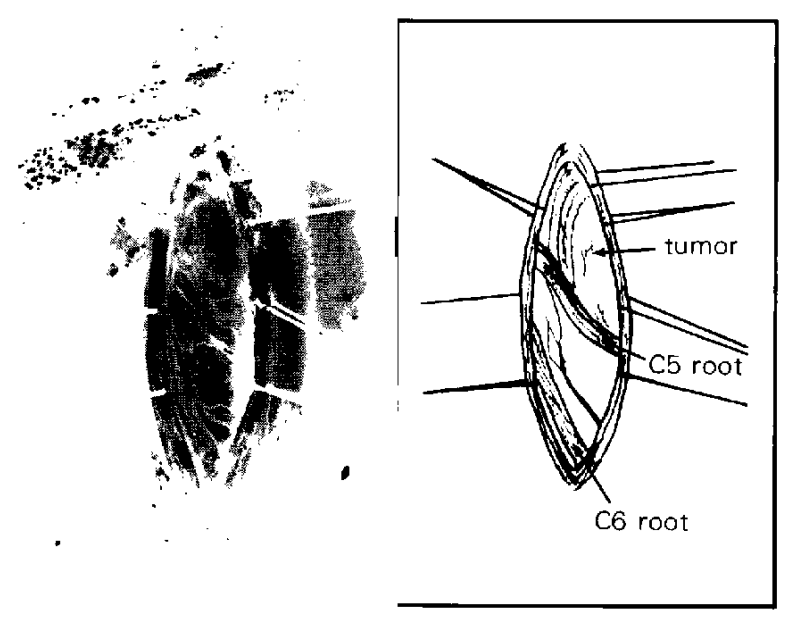

Fig. 2 Photograph taken during surgery (left) and corresponding diagram (right) show that this tumor was compressing the spinal cord ventromedially.

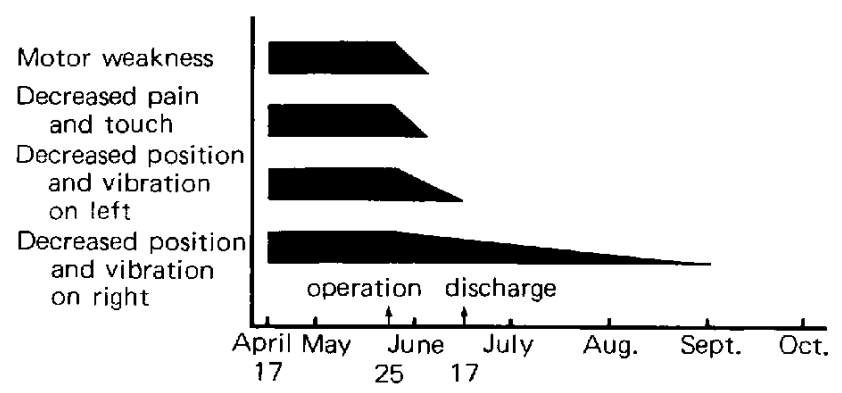

Fig. 3 Pre- and postoperative course (signs and symptoms). Note the prolonged recovery of position and vibration sensations on the right side.

the right $\mathrm{C} 4$ root and compressing the spinal cord ventromedially was totally removed (Fig. 2 ). The patient's clinical course is illustrated in Fig. 3. The motor weakness in the right upper and lower extremities gradually disappeared over the 2 weeks following surgery. During that period, the decreased superficial pain and touch sensations also improved. The lowered position and vibration sensations on the left side gradually improved to normal within 3 weeks after surgery; those on the right side improved somewhat more slowly. However, restoration of position and vibration sensations in the right hand and foot took 4 months after operation, and the thumb and fingers recovered slightly faster than the toes.

Recording procedure and findings of SL-SEPs: SL-SEPs were recorded on five occasions while the patient was hospitalized and twice thereafter. At each recording the left and right median nerves were independently stimulated at the wrist, via an isolation unit (Nihon Koden), with a $0.3 \mathrm{msec}$ square pulse wave at a rate of 3.7 pulses per second. The stimulus intensity was just enough to produce a twitch of the thumb. The recording electrode was placed on the scalp at $\mathrm{Cz}$ point (international 10-20 system) and the noncephalic reference electrode on the left knee.

The input from the recording electrode was amplified by a differential preamplifier with a band width of $100 \mathrm{~Hz}$ to $1 \mathrm{kHz}$, and 1,000 samples were summated by a Sanei 7T08 signal processor over an analysis time of $51.2 \mathrm{msec}$. The summated responses were superimposed to ensure reproducibility and were recorded by a X-Y plotter.

The SL-SEPs were classified and labeled as follows. The four positive potentials were $\mathrm{P}_{1}, \mathrm{P}_{2}, \mathrm{P}_{3}$, and $\mathrm{P}_{4}$ and the three negative ones were $\mathrm{N}_{1}, \mathrm{~N}_{2}$, and $\mathrm{N}_{3}$. Normal peak latencies for these potentials were obtained from 23 healthy subjects and are listed in 


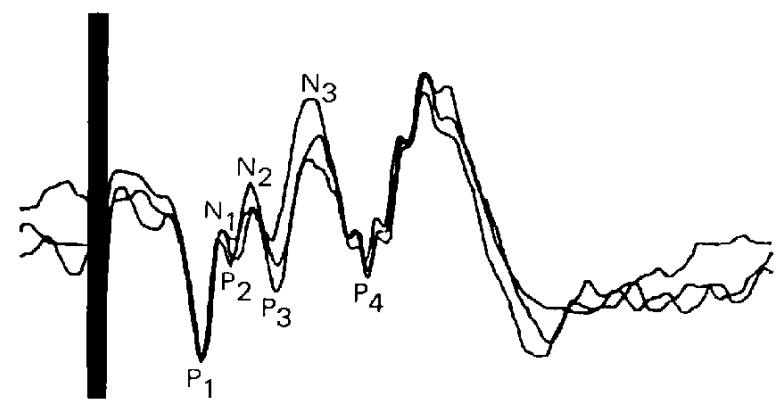

Fig. 4 Classification of potentials and their peak latencies. $P_{1}: 7.9 \pm 0.5 \mathrm{msec}, \mathrm{N}_{1}: 9.6 \pm 0.5 \mathrm{msec}$, $P_{2}: \quad 10.4 \pm 0.6 \mathrm{msec}, N_{2}: 11.4 \pm 0.6 \mathrm{msec}, P_{3}$ : $12.8 \pm 0.8 \mathrm{msec}, \mathrm{N}_{3}: 15.7 \pm 0.8 \mathrm{msec}, P_{4}: 19.1$ $\pm 1.1 \mathrm{msec}$.

Fig. 4. Our $P_{1}, P_{2}$, and $P_{3}$ approximately correspond to $P_{9}, P_{11}$, and $P_{13}$ in Anziska and Cracco's study. ${ }^{2,3)}$

The first SL-SEPs were recorded on May 10, about 2 weeks before surgery, and on both sides only $P_{1}$ and $N_{1}$ potentials with prolonged latencies were identified (Table 1 and Fig. 5). On the fifth recording (June 17), potentials appearing after $N_{1}$ and having quite prolonged peak latencies were first recognized on the left side. Position and vibration sensations on the left side had already improved by this time.

The right position and vibration sensations had reached the normal range by September 5, when potentials following $\mathrm{N}_{1}$ appeared on the right side. All peak latencies had approached normal ranges on the left side, but not on the right. The last recording, on October 21, showed that peak latencies for all potentials on both sides were within normal ranges, with the exception of $P_{3}$.

\section{Discussion}

Since $\mathrm{Cracco}^{5,6)}$ first recorded SL-SEPs in man, using a noncephalic reference, many researchers ${ }^{1,8,12-16,19)}$ have attempted to ascertain the primary generators of these potentials. Their results suggest that SLSEPs are generated primarily by sources within the dorsal column medial lemniscal system. This can be theoretically determined by calculating the conduction velocity of the stimulated nerve and spinal cord. ${ }^{7,10)}$

In our patient, position and vibration sensations were more severely disturbed and took a longer time to improve after surgery than did motor function and superficial sensations. Sequential recordings of SL-SEPs in this patient revealed that the recovery of SL-SEPs paralleled the improvement in vibration and position sensations but not that of motor function and superficial sensations. Clinical improvement in vibration and position sensations was observed prior to the recovery of peak latencies of the respective potentials. These findings indicate that SL-SEPs are more closely related to deep sensation, which is conveyed in the dorsal column medial lemniscal system. We postulate that the tumor compressing the spinal cord at the $\mathrm{C} 4$ level impaired the dorsal column more than other structures, such as the lateral corticospinal tract and the spinothalamic system.

During the period in which deep sensation was severely compromised, only $P_{1}$ and $N_{1}$ potentials were recorded in the SL-SEPs. Our $\mathrm{P}_{1}$ component is analogous to the $P_{9}$ potential, which is widely considered to originate from the brachial plexus or peripheral nerve. On the other hand, our $\mathrm{P}_{2}$ potential

Table 1 Peak latencies of SL-SEPs in our patient

\begin{tabular}{|c|c|c|c|c|c|c|c|c|}
\hline Date & $\underset{\text { side }}{\text { Stimulation }}$ & $\begin{array}{c}P_{1} \\
(7.9 \pm 0.5)\end{array}$ & $\begin{array}{c}\mathrm{N}_{1} \\
(9.6 \pm 0.5)\end{array}$ & $\begin{array}{c}\mathrm{P}_{2} \\
(10.4 \pm 0.6)\end{array}$ & $\begin{array}{c}\mathrm{N}_{2} \\
(11.4 \pm 0.6)\end{array}$ & $\begin{array}{c}\mathrm{P}_{3} \\
(12.8 \pm 0.8)\end{array}$ & $\begin{array}{c}\mathrm{N}_{3} \\
(15.7 \pm 0.8)\end{array}$ & $\begin{array}{c}\mathrm{P}_{4} \\
(19.1 \pm 1.1)\end{array}$ \\
\hline \multirow[t]{2}{*}{ May 10, ' 83} & $\mathrm{R}$ & 8.8 & 10.4 & - & - & - & - & - \\
\hline & $\mathbf{L}$ & 9.0 & 10.6 & - & - & - & - & - \\
\hline \multirow[t]{2}{*}{ May 26} & $\mathbf{R}$ & 8.6 & 10.6 & - & - & - & - & - \\
\hline & $\mathbf{L}$ & 8.8 & 10.6 & - & - & - & - & - \\
\hline \multirow[t]{2}{*}{ May 31} & $\mathrm{R}$ & 9.0 & 10.8 & - & - & - & - & - \\
\hline & $\mathbf{L}$ & 9.2 & 10.8 & - & - & - & - & - \\
\hline \multirow{2}{*}{ June 4} & $\mathrm{R}$ & 8.6 & 10.4 & - & - & - & - & - \\
\hline & $\mathrm{L}$ & 8.6 & 10.0 & - & - & - & - & - \\
\hline \multirow[t]{2}{*}{ June 17} & $\mathrm{R}$ & 9.2 & 10.6 & - & - & - & - & - \\
\hline & $\mathbf{L}$ & 9.4 & 10.8 & 12.4 & 13.6 & 15.2 & 17.8 & 21.2 \\
\hline \multirow[t]{2}{*}{ September 5} & $\mathbf{R}$ & 9.0 & 11.4 & 12.4 & 13.6 & 15.8 & 19.0 & 21.8 \\
\hline & $\mathrm{L}$ & 9.0 & 10.6 & 11.6 & 13.0 & 15.0 & 17.6 & 20.0 \\
\hline \multirow[t]{2}{*}{ October 21} & $\mathbf{R}$ & 8.8 & 9.5 & 10.5 & 11.4 & 15.0 & 17.0 & 20.6 \\
\hline & $\mathbf{L}$ & 8.8 & 10.0 & 10.6 & 11.6 & 14.2 & 16.8 & 20.6 \\
\hline
\end{tabular}



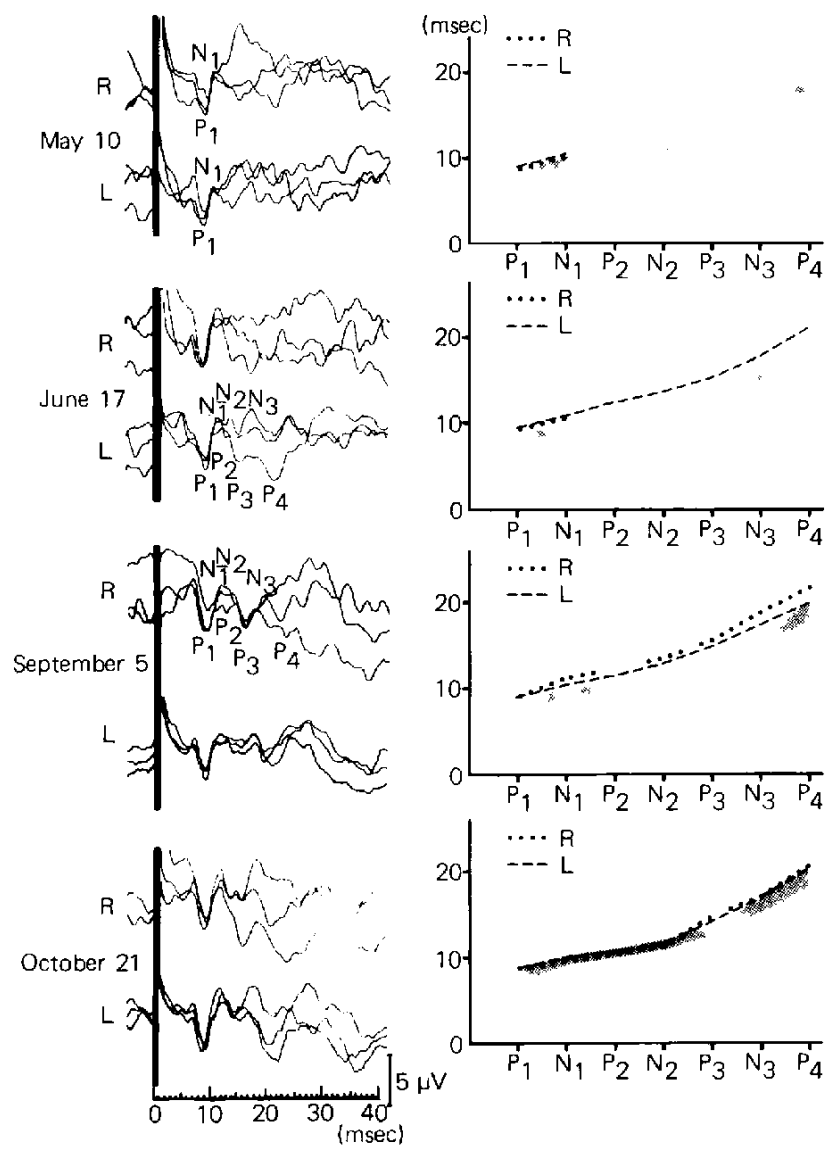

Fig. 5 left: Recording of SL-SEPs. right: Peak SLSEP latencies. Shaded zones indicate the range of standard deviation in normal subjects. Note that all components of SL-SEPs on the patient's left side were first recorded on June 17 and those on the right side on September 5 .

corresponds to the $P_{11}$ potential, ${ }^{2,3)}$ which may be primarily generated from the root entry zone $e^{|9|}$ or the dorsal column. ${ }^{4-7)}$ In our case, removal of the tumor was followed by clinical improvement in deep sensation and the appearance of $\mathrm{P}_{2}$ and other later potentials. This suggests that $P_{2}$ potentials may originate in the dorsal column or its nuclear structures. Another possibility is that excision of the tumor restored axonal conduction to the primary generator of $\mathrm{P}_{2}$, which is located rostral to the tumor.

We reviewed the literature on SL-SEPs in patients with cervical lesions and found that only two other cases have so far been reported. ${ }^{11,18)}$ These cases involved a dislocation fracture of the odontoid process and an intramedullary lesion. In these patients the $P_{2}$, or $P_{11}$, potential was not detected; however, neither the precise location of the lesions nor the clinical signs were clearly described. We feel that more reports on SL-SEPs in patients with well localized lesions and well documented clinical data are necessary to identify the primary generators and to define the clinical role of SL-SEPs.

\section{References}

1) Allison $T$, Hume AL: A comparative analysis of short-latency somatosensory evoked potentials in man, monkey, cat and rat. Exp Neurol 72: 592-611, 1981

2) Anziska B, Cracco RQ: Short latency somatosensory evoked potentials: Studies in patients with focal neurological disease. Electroencephalogr Clin Neurophysiol 49: 227-239, 1980

3) Anziska BJ, Cracco RQ: Short latency SEPs to median nerve stimulation: Comparison of recording methods and origin of components. Electroencephalogr Clin Neurophysiol 52: 531-539, 1981

4) Chappa KH, Choi SK, Young RR: Short-latency somatosensory evoked potentials following median nerve stimulation in patients with neurological lesions, in Desmedt JE (ed): Progress in Clinical Neurophysiology, vol 7. Basel, Karger, 1980, pp 264281

5) Cracco RQ: Spinal evoked response: Peripheral nerve stimulation in man. Electroencephalogr Clin Neurophysiol 35: 379-386, 1973

6) Cracco RQ, Cracco JB: Somatosensory evoked potential in man: Far field potentials. Electroencephalogr Clin Neurophysiol 41: 460-466, 1976

7) Desmedt JE, Cheron G: Central somatosensory conduction in man: Neural generators and interpeak latencies of the far field components recorded from neck and right or left scalp and earlobes. Electroencephalogr Clin Neurophysiol 50; 382-403, 1980

8) El-Negamy E, Sedwick EM: Properties of a spinal somatosensory evoked potential recorded in man. $J$ Neurol Neurosurg Psychiatry 41: 762-768, 1978

9) Goff WR, Rosner BS, Allison T: Distribution of cerebral somatosensory evoked responses in normal man. Electroencephalogr Clin Neurophysiol 14: 697713, 1962

10) Jones SJ: Short latency potentials recorded from the neck and scalp following median nerve stimulation in man. Electroencephalogr Clin Neurophysiol 43: 853863, 1977

11) Jones SJ: Investigation of brachial plexus traction lesions by peripheral and spinal somatosensory evoked potentials. J Neurol Neurosurg Psychiatry 42: 107116,1979

12) Kimura J, Yamada T, Kawamura H: Central latencies of somatosensory cerebral evoked potentials. Arch Neurol 35: 683-688, 1978

13) Kritchevsky M, Wiederholt WC: Short-latency somatosensory evoked potentials. Arch Neurol 35: 706-711, 1978

14) Lessor RP, Lueders H, Hahn J, Klem G: Early 
somatosensory potentials evoked by median nerve stimulation: Intraoperative monitoring. Neurology (NY) 31: 1519-1523, 1981

15) Mauguere F, Courjon J: The origins of short-latency somatosensory evoked potentials in humans. Ann Neurol 9: 607-611, 1981

16) Shimoji $\mathrm{K}$, Shimizu $\mathrm{H}$, Maruyama $\mathrm{Y}$ : Origin of somatosensory evoked responses recorded from the cervical skin surface. $J$ Neurosurg 48: 980-984, 1978

17) Stockard JJ, Sharbrough FW: Unique contributions of short-latency auditory and somatosensory evoked potentials to neurologic diagnosis, in Desmedt JE (ed): Progress in Clinical Neurophysiology, vol 7. Basel, Karger, 1980, pp 231-263
18) Synek VM, Cowan JC: Somatosensory evoked potentials in patients with supraclavicular brachial plexus injuries. Neurology (NY) 32: 1347-1352, 1982

19) Yamada T, Kimura J, Nitz DM: Short latency somatosensory evoked potentials following median nerve stimulation in man. Electroencephalogr Clin Neurophysiol 48: 367-376, 1980

Address reprint requests to: T. Yokoyama, M.D., Department of Neurosurgery, Hamamatsu University School of Medicine, 3,600 Handa-cho, Hamamatsu, Shizuoka 431-31, Japan. 